\title{
The role of rumination in the occurrence of positive effects of experienced traumatic events
}

\section{BACKGROUND}

Cognitive processes play a significant role in both the negative and positive consequences of traumatic experiences. The aim of this research was to investigate the role of rumination in the occurrence of positive effects, in the form of posttraumatic growth, of experienced traumatic events.

\section{PARTICIPANTS AND PROCEDURE}

Data were collected from 227 subjects who had experienced traumatic events, including cancer patients (31.30\%), women who had experienced domestic violence (39.20\%), and medical rescue workers exposed to traumatic events at work $(29.50 \%)$. The age of participants ranged from 19 to 67 years $(M=40.12, S D=13.28)$. The Posttraumatic Growth Inventory was used to measure positive changes, and the Event Related Rumination Inventory was used to assess the two types of ruminations (intrusive and deliberate).

\section{RESULTS}

Both types of ruminations (intrusive and deliberate) were positively correlated with the level of posttraumatic growth in the group of cancer patients, and deliberate ruminations were associated with posttraumatic growth in the group of women who had experienced domestic violence and in the medical rescue workers. The results of regression analysis confirmed a significant role of deliberate rumination.

\section{CONCLUSIONS}

The study of ruminations allows us to better explain the mechanisms underlying the consequences of traumatic experiences.

KEY WORDS

posttraumatic growth; ruminations; traumatic events 


\section{BACKGROUND}

\section{THE POSTTRAUMATIC GROWTH PHENOMENON}

Experiencing traumatic events is usually associated with negative consequences, the most often discussed of which is posttraumatic stress disorder (PTSD). Recently, it has been pointed out that experiencing such events may also cause positive effects, defined as posttraumatic growth.

Posttraumatic growth (PTG) is the occurrence of positive changes as a result of trying to cope with the consequences of traumatic events (Tedeschi \& Calhoun, 1996, 2004). As such, posttraumatic growth is something more than just returning to a state of equilibrium after a traumatic experience. This phenomenon is when an individual, as a result of their experience, undergoes some kind of a transformation, and they reach a level of functioning that is higher than it was before experiencing the trauma.

Tedeschi and Calhoun (1996, 2004) $)^{1}$ suggest three groups of positive changes which constitute posttraumatic growth. They include changes in self-perception, interpersonal relations and philosophy of life. A higher sense of self-worth, of efficacy, and more self-confidence, as well as beliefs about one's abilities to cope - both now and in the future - may be the result of successfully dealing with a traumatic experience. As a result of a traumatic event, some people see new possibilities in life and set new goals, and discover within themselves new resources of sensitivity and empathy towards others. Individuals who experience growth as a result of traumatic events pay more attention to small, everyday events, and the importance of major life issues that were previously important seems to diminish.

Experiencing trauma may also result in a change in the existential (religious) beliefs of an individual As a result of the struggle with critical events, they may appreciate life more, and live it more consciously (Tedeschi \& Calhoun, 2007).

Posttraumatic growth does not mean that experiencing trauma is something positive, or required for making significant changes in one's life. Nor should it be considered equivalent to a sense of happiness. However, it is a chance for a more purposeful and valuable life. Also, one should not expect that every individual who has experienced trauma will experience such growth, or that it is a necessary prerequisite to full recovery after experiencing trauma. It is not the trauma itself that leads to growth, but rather the activity undertaken by the individual in order to cope with the crisis (Tedeschi \& Calhoun, 2007).

\section{RUMINATION AND THE OCCURRENCE OF POSITIVE POSTTRAUMATIC CHANGES}

The processes of occurrence of both negative and positive consequences of traumatic events are associated with the engagement of cognitive processes, which include rumination in particular. Ruminations are understood as unwelcome thoughts of a repetitive and intrusive character recurring without any clear reason (Cann et al., 2011). It is included in the posttraumatic growth model developed by the creators of the concept (Calhoun, Cann, Tedeschi, \& McMillan, 2010; Tedeschi \& Calhoun, 2004; cf. also Ogińska-Bulik, 2013a). Rumination is treated as a factor leading to growth, but - as stressed by Calhoun, Cann, Tedeschi, and McMillan (2000) - the engagement of cognitive processes, including rumination, is not a necessary prerequisite for the occurrence of positive posttraumatic changes (though it is desired). One of the causes of rumination is perseverative cognitive processing, defined as repetitive or chronic activation of cognitive stressors (Cann et al., 2011).

Ruminations have been of interest to researchers for many years, but until now there has been no uniform concept of their nature and causes. One of the better known concepts is that of Martin and Tesser (1996), who proposed that ruminations are the effect of the disruption of goal-oriented activity and they occur when there is a discrepancy between a person's expectations and actual advances towards goal fulfilment. Baryła and Wojciszke (2005) extend this concept, treating ruminations as a state of recurring, negative thoughts about one's actions, which stem not only from the discrepancy between one's goals and their level of achievement, but also from a discrepancy between general and normative beliefs about one's self and the world, and the information about the actual states of one's self and the world. The aforementioned researchers assume the existence of two types of rumination content: one regarding the social world and the other regarding one's self. Such a definition of rumination has been operationalised in the Rumination Questionnaire developed by these authors. It is treated like a disposition - that is, a relatively stable property of an individual.

Rumination is also associated with other cognitive processes and emotions experienced by an individual. According to Nolen-Hoeksema (2000), the ruminative type of thinking is a passive and persistent concentration of one's attention on perceived negative emotions, their causes and effects, and - importantly - happening without undertaking efforts to try to change them. This tendency to maintain a dysphoric mood is relatively stable, which is why we can talk about a ruminative style of reacting or thinking. It is a typical "chewing" of one's thoughts which 
does not lead to any action or changes in behaviour. This type of 'depressive rumination' can be treated as a dysfunctional way of emotional regulation (Nolen-Hoeksema, Wisco, \& Lyubomirsky, 2008). The opposite of this ruminating style of reaction is the distractive style, associated with a lack of attention and distracting oneself, as well as analysing and undertaking actions which aim to change or reduce the experienced negative emotions.

A modification of the Nolen-Hoeksema concept takes into account another way to react to a dysphoric mood - reflective thinking. It is problem-solving oriented and consists of concentration of one's emotions, and, most of all, on efforts to understand their determinants and changing a strategy for action in a given area. Engaging in such deliberate thinking may lead to the improvement of one's mood (Treynor, Gonzales, \& Nolen-Hoeksema, 2003; Jarmakowski, 2011).

An attempt to classify rumination was also made by Watkins (2008, also cf. Jarmakowski, 2011), who taking into account the level of abstractness of the ruminating thoughts - distinguishes between concrete and abstract ruminations. He describes the former as cognitive schemata regarding oneself, which are abstract, generalised, and detached from the situational context. It is this type of rumination that is associated with negative emotions. The latter are cognitive schemata regarding one's self which are specific and connected to a concrete situation. This type of rumination serves for undertaking actions that aim to solve the problem. The author emphasizes, however, that these patterns were observed predominantly in depressive individuals (though they were also partially confirmed in non-clinical groups).

Hence, ruminations can be considered in two ways. The first describes ruminations as recurrent thoughts of an auto-critical and self-judgemental character. It is therefore a kind of disposition for examining oneself and the world, in a specific way which is not directly related to actions currently being performed, nor does it contribute to understanding or explaining the current situation. The second way treats ruminations as the tendency of an individual to consider/examine a concrete, usually negative, life situation. Here, the concept of rumination is limited to the "chewing" of negative content associated with recent unpleasant life events, which, as a consequence, may lead to lowering one's mood and foster an increase in depressive symptoms (Cann et al., 2011; McIntosh \& Martin, 1992; Nolen-Hoeksema, 2000; Radoń, 2014).

Ruminations, especially those regarding a specific event, may play diverse roles. Some may be of a more destructive character, which is unrelated to attempts to solve a problem, whereas others may have a constructive character, favouring the thorough analysis of a situation in order to find ways to solve it. Such a distinction is operationalised by American researchers who have developed a tool for the measurement of rumination: the Event Related Rumination Inventory - ERRI (Cann et al., 2011). The authors concentrate on ruminations associated with an experienced negative life event, and not on a general disposition towards a ruminative type of thinking - distinguishing between intrusive ruminations, which are of an automatic, uncontrolled character, and reflexive, deliberate rumination, which serves to search for ways to cope with the experienced negative life event. Ruminations of an intrusive character, regarding an experienced trauma, are treated as dysfunctional cognitive ways of coping, which may foster the persistence of posttraumatic stress symptoms (Cann et al., 2011; Ehlers \& Clark, 2000; Ehring \& Ehlers, 2014). In turn, deliberate ruminations serve for 'working through the trauma' and are treated as a factor fostering the occurrence of positive (growthtype) posttraumatic changes (Calhoun, Cann, Tedeschi, \& McMillan, 2010; Cann et al., 2011; Taku, Calhoun, Cann, \& Tedeschi, 2008).

Results of American research (Cann et al., 2011) confirm the relationship between rumination and PTSD. They showed a positive relationship both between intrusive and deliberate ruminations (analysed twice - just after the traumatic event, and in the weeks directly preceding the study) and all three dimensions of the Impact of Event Scale, used to assess the intensity of stress symptoms - that is intrusion, hyperarousal and avoidance. A stronger relationship was observed for intrusive ruminations. Similar results were obtained from Polish research adapting the Event Related Rumination Inventory (Ogińska-Bulik \& Juczyński, 2015).

The role of ruminations in the occurrence of positive posttraumatic changes seems particularly important. This issue is a new direction of research. Currently available research, most of which is of a cross-sectional character, indicates a positive relationship between cognitive processes and the occurrence of positive posttraumatic changes. Cognitive processes, including mainly ruminations (but also reflexivity and intrusions), turned out to be positively correlated with posttraumatic growth in HIV patients who developed AIDS (Bower, Kemeny, Taylor, \& Fahey, 1998), in individuals who experienced heart attacks (Gangstad, Norman, \& Barton, 2009), spouses of individuals who had experienced heart attacks (Senol-Durak \& Ayvasik, 2010), women suffering from cancer (Chan, Ho, Tedeschi, \& Leung, 2011), individuals who had experienced different types of cancer (Morris \& Shakespeare-Finch, 2011) and grieving individuals (Boyraz, Home, \& Sayger, 2010). Moreover, a positive correlation between ruminations and posttraumatic growth was found in a group of students who had lost someone close (Michael \& Snyder, 2005) and in a group who had experienced different kinds
The role of rumination in the occurrence of positive effects of experienced traumatic events 
of traumatic events (Lindstrom, Cann, Calhoun, \& Tedeschi, 2013; Stockton, Hunt, \& Joseph, 2011).

Data confirming positive correlations between ruminations and the occurrence of positive posttraumatic changes were also provided by longitudinal research. Kleim and Ehlers (2009) reported that ruminations assessed two weeks after experiencing assault predicted posttraumatic growth assessed 6 months later. Similarly, research on amputees showed that ruminations predicted positive posttraumatic changes, measured after 12 months (Phelps, Williams, Raichle, Turner, \& Ehde, 2009). The relation between ruminations and positive changes was also observed in a group of children. Research by Kilmer and Gil-Rivas (2010) suggests that in 7-10-year-old victims of Hurricane Katrina, ruminations (mainly intrusive) were a predictor of posttraumatic growth in a year's time after the event.

Most research in this area indicates a significant role of predominantly deliberate ruminations. American research conducted with students who had experienced severely stressful life events 6-8 months before the study suggests that both types of rumination were positively correlated with posttraumatic growth (Calhoun et al., 2010). However, there was a stronger relationship with regard to deliberate ruminations. Similar relationships were observed in cardiological patients who took part in a cardiac rehabilitation programme (Gerwe, 2014), and in a group of Japanese students (Taku et al., 2008; Taku, Cann, Tedeschi, \& Calhoun, 2009).

Polish research (Ogińska-Bulik \& Juczyńki, 2015) conducted in order to adapt the Event Related Rumination Inventory provided data which suggest that intrusive ruminations were positively (though weakly) correlated with the overall score on the Posttraumatic Growth Inventory and two of its factors, i.e. change in self-perception and relations with others. In turn, deliberate ruminations were associated with all areas of posttraumatic stress.

Results of research on rescue-service workers confirm the positive correlation between ruminations and the occurrence of positive effects of experienced trauma (Ogińska-Bulik, 2015). Both types of rumination were positively correlated with the levels of posttraumatic growth, but there was a stronger correlation for deliberate ruminations. They predicted the overall score of posttraumatic growth measured using the Posttraumatic Growth Inventory, and for the three areas of changes in self perception, relations with others, and the appreciation of life.

Some studies of the relation between ruminations and posttraumatic growth take into account the time when they occur. Some show a relationship between posttraumatic growth and ruminations occurring immediately after the experienced event (Calhoun et al., 2010; Taku et al., 2008), some with the later ruminations, measured 2-3 weeks prior to the study (Cann,
Calhoun, Tedeschi, \& Solomon, 2010). There are also studies that provide evidence that both earlier and later ruminations are associated with posttraumatic growth (Cann et al., 2011; Lindstrom et al., 2013; Nightingale, Sher, \& Hansen, 2010; Taku et al., 2009).

There also exist studies that indicate no such relation between ruminations and posttraumatic growth, as well as the existence of a negative relationship between these variables. These were reviewed by Stockton (2012). For instance, ruminations of an intrusive character did not have a predictive role for posttraumatic growth in a study on Japanese students (Taku et al., 2008, 2009), and American students (Cann et al., 2011). Longitudinal research on leukaemia patients showed that intrusive ruminations assessed during treatment did not predict posttraumatic growth after treatment was complete (Carboon, Anderson, Pollard, Szer, \& Seymour, 2005). Similarly, Salsman, Segerstrom, Brechting, Carlson, and Andrykowski (2009) found that in a group of individuals suffering from colon cancer, the baseline level of intrusive and deliberate ruminations did not predict growth measured 3 months later.

Park, Chmielewski, and Blank (2010) provided evidence indicating negative correlations between intrusive ruminations and the occurrence of positive changes as a result of experienced trauma in individuals suffering from cancer. Research by Cann et al. (2010) suggests that, among students who had experienced various life events, recent ruminations (those in the period immediately before the study) were negatively correlated with posttraumatic growth. Other research conducted on a group of students (Cann et al., 2011) showed a negative correlation between ruminations (treated as a relatively stable feature of an individual) and posttraumatic growth. This suggests that the general tendency for concentration on threats and potential losses may hinder the occurrence of positive posttraumatic changes. Inconclusive results regarding the relationship between cognitive processes and positive consequences of trauma could be a result of different conceptualisations of cognitive processes, as well as the use of different tools for measurement.

\section{PARTICIPANTS AND PROCEDURE}

The inconclusive nature of the previous results and the lack of Polish data in this area led us to undertake research aimed at determining the role of rumination in the occurrence of positive effects of experienced traumatic events. We looked for answers to the following research questions:

- To what extent does posttraumatic growth occur in individuals who have experienced traumatic events?

- How intense were the ruminations regarding the experienced event? 
- Do sociodemographic variables such as the sex and age of subjects as well as the type of experienced event influence the levels of the analysed variables?

- Are the levels of rumination associated with the intensity of posttraumatic growth?

- Which of the two types of ruminations (intrusive, deliberate) can predict posttraumatic growth?

It is assumed that both types of rumination are positively correlated with levels of posttraumatic growth; however, it is expected that stronger correlations will be found for deliberate ruminations, which will also predict posttraumatic growth.

Two hundred and sixty individuals (3 groups) who had experienced traumatic event in the five years before the study took part. After excluding incorrectly completed questionnaires and individuals for whom the experienced event did not have a traumatic character, 227 individuals were qualified for the analysis. These were cancer patients (both sexes, $31.30 \%$ of the subjects), women who had experienced domestic violence $(39.20 \%)$ and paramedics who had experienced traumatic events in association with their job (exclusively men, $29.50 \%$ ). The research study was conducted in appropriate facilities in central Poland. It was anonymous, and informed consent was obtained from the participants before completing the questionnaires. Individuals suffering from cancer were studied in two oncology clinics and one oncology unit in a hospital. Women who had experienced violence at home were studied in centres for support for victims of domestic violence. The paramedics were studied at their workplaces, i.e. Wojewódzka Stacja Ratownictwa Medycznego [Voivodeship Medical Rescue Station].

The age of the participants ranged between 19 and $67(M=40.12, S D=13.28)$. The majority of participants were women (63.30\%). Two measurement tools were used: the Posttraumatic Growth Inventory and the Event Related Rumination Inventory.

The Posttraumatic Growth Inventory (PTGI), designed by Tedeschi and Calhoun (1996), was adapted to Polish conditions by Ogińska-Bulik and Juczyński (2010). The tool consists of 21 statements describing various positive changes that occurred as a result of a negative life event or trauma (e.g. I changed my priorities about what is important in life), towards which a participant ought to assume an attitude by choosing answers ranging from I did not experience such change ( 0 points) to I experienced such change to a great degree (5 points). The higher the score, the higher the intensity of the positive changes. The Polish version of the tool measures 4 factors that constitute posttraumatic growth. These are: changes in self-perception, changes in relations with others, greater appreciation of life and spiritual changes. The overall score is a sum of the four aforementioned factors. The tool has satisfactory psychometric prop- erties. The Cronbach's $\alpha$ of the tool is .93 (it ranges between .63 and .87 for the separate factors), and it is slightly higher than for the original version.

The Event Related Rumination Inventory (ERRI) was developed by Cann et al. (2011) and adapted to Polish conditions by Ogińska-Bulik and Juczyński (2015). It is a tool used to assess the intensity of rumination associated with experienced negative life events. The Polish adaptation of ERRI consists of two scales, each of them consisting of 10 statements. The first one is concerned with intrusive ruminations (e.g. "I thought about the event when I did not mean to"), while the second deals with deliberate ruminations (e.g. "I thought about whether I could find meaning from my experience"). A participant has to assess each statement on a 4-level Likert scale $(0-$ not at all, 1 - rarely, 2 - sometimes, 3 - often), regarding the frequency of occurrence of situations described in the inventory in a period of a few weeks after the experienced event. Scores are calculated separately for each of the two scales. The coefficients of internal validity, assessed using Cronbach's $\alpha$, are high: .96 for intrusive ruminations and .92 for the deliberate ruminations scale. They are higher than for the original version of the tool, where they were .94 and .88 (Cann et al., 2011).

\section{RESULTS}

Analyses were conducted to assess the normal distribution and determine the means of the analysed variables, taking into account sex, age and the type of experienced traumatic events. The distribution of results was close to normal (we used the Kolmogorov-Smirnov test), which allows us to use parametric tests. Next, using the Pearson's $r$ correlation coefficients, we established relationships between variables and assessed - using regression analysis (stepwise progressive) - which type of rumination predicts posttraumatic growth. The means of the analysed variables across all participants are presented in Table 1 .

The mean scores of the participants for both types of ruminations correspond to the value of 5 sten (Ogińska-Bulik \& Juczyński, 2015); therefore they can be considered average results. The intensity of deliberate ruminations is slightly higher, but it does not differ significantly from the levels of intrusive ruminations. More detailed analysis of the data revealed that, in line with the norms developed for the Polish adaptation of the ERRI (Ogińska-Bulik \& Juczyński, 2015), 84 subjects were characterised by low levels of intrusive ruminations (that is $37.00 \%$ of participants), $82(36.10 \%)$ by medium levels and $61(26.90 \%)$ by high levels. In turn, for deliberate ruminations, 79 participants $(34.80 \%)$ had low levels of such ruminations, $72(31.70 \%)$ had average levels and $76(33.50 \%)$ had high levels.
The role of rumination in the occurrence of positive effects of experienced traumatic events 
Table 1

Intensity of ruminations and posttraumatic growth in the entire group of participants

\begin{tabular}{lcc}
\hline & $M$ & $S D$ \\
\hline Intrusive ruminations & 14.81 & 8.88 \\
Deliberate ruminations & 15.27 & 7.66 \\
Posttraumatic growth - overall & 53.22 & 2.74 \\
$\quad$ changes in self-perception & 21.86 & 9.64 \\
changes in relations with others & 18.62 & 8.49 \\
appreciation of life & 8.82 & 3.90 \\
$\quad$ spiritual changes & 3.92 & 3.22 \\
\hline
\end{tabular}

In accordance with the norms developed for the Polish adaptation of the PTGI (Ogińska-Bulik \& Juczyński, 2010), the participants' results regarding posttraumatic growth should be regarded as low - they can be placed in the upper limit of the $4^{\text {th }}$ sten. One participant did not report any positive changes resulting from the experienced trauma. The mean is lower than scores of participants who took part in the normalising research associated with development of the Polish adaptation of the tool (Ogińska-Bulik \& Juczyński, 2010), i.e. mothers of children suffering from leukaemia $(M=73.24, S D=17.60)$ or parents of children with Down's syndrome $(M=67.20$, $S D=22.30)$, but similar to the results obtained from policemen $(M=53.46, S D=18.40)$ or soldiers who took part in peace missions $(M=55.12, S D=21.20)$. More detailed analysis revealed that 108 participants (47.60\% of participants) had low levels of posttraumatic growth, $71(31.30 \%)$ had average and $48(21.10 \%)$ high. Participants showed similar levels of change in each of the separate areas that constitute posttraumatic growth (means of separate factors divided by the number of items within a given factor do not differ from each other statistically significantly and are equal to: for self-perception $-M=2.42$, for relations with others $-M=2.66$, appreciating life $-M=2.95$, and spiritual changes $-M=1.96$ ).

Sex differentiates both the intensity of ruminations and positive posttraumatic changes (Table 2). Women scored higher on both types of rumination, as well as posttraumatic growth. The results of the normalisation research also suggested a higher tendency towards rumination in women (OgińskaBulik \& Juczyński, 2015), as well as a higher ability to benefit from traumatic events (Ogińska-Bulik \& Juczyński, 2010).

Age differentiates neither the intensity of any of the analysed types of rumination, nor the levels of positive posttraumatic changes, except for relations with others. Higher scores for relations with others were observed among the older participants $(M=20.27$, $S D=8.05)$ in comparison with younger ones $(M=16.97, S D=8.64, t=-1.20, p<.010)$. Similarly, age did not differentiate between the analysed types of rumination in the normalisation research (Ogińska-Bulik \& Juczyński, 2015). It was found that, among the older participants, there were more instances of positive changes in relationships with others and the spiritual sphere in comparison with the younger participants. No differences were observed in terms of self-perception and appreciation of life (Ogińska-Bulik \& Juczyński, 2010).

The intensity of the ruminations and the levels of positive posttraumatic changes were differentiated by the type of experienced traumatic event (Table 3). Paramedics scored significantly lower on both types of rumination. This group also scored lower on posttraumatic growth in comparison to cancer patients and women who had experienced domestic violence.

The following analysis served to assess whether there is a correlation between the intensity of ruminations and the levels of positive posttraumatic changes. The results of all participants, as well as the separate groups, are presented in Table 4.

The results suggest a positive correlation between ruminations, especially those of a deliberate char-

Table 2

Intensity of ruminations and posttraumatic growth depending on the sex of participants

\begin{tabular}{|c|c|c|c|c|c|c|}
\hline \multirow{2}{*}{ Variable } & \multicolumn{2}{|c|}{ Men $(n=83)$} & \multicolumn{2}{|c|}{ Women $(n=144)$} & \multirow[t]{2}{*}{$t$} & \multirow[t]{2}{*}{$p$} \\
\hline & $M$ & $S D$ & $M$ & $S D$ & & \\
\hline Intrusive ruminations & 9.41 & 7.84 & 17.92 & 7.92 & -7.82 & .001 \\
\hline Deliberate ruminations & 11.04 & 6.68 & 17.71 & 7.12 & -6.93 & .001 \\
\hline Posttraumatic growth - overall & 45.91 & 23.19 & 57.42 & 19.74 & -3.96 & .001 \\
\hline changes in self-perception & 19.30 & 10.07 & 23.33 & 9.10 & -3.09 & .010 \\
\hline changes in relations with others & 15.98 & 9.00 & 20.13 & 7.82 & -3.63 & .001 \\
\hline appreciation of life & 7.74 & 4.05 & 9.44 & 3.68 & -3.20 & .001 \\
\hline spiritual changes & 2.87 & 3.05 & 4.52 & 3.18 & -3.80 & .001 \\
\hline
\end{tabular}


Table 3

Intensity of ruminations and posttraumatic stress depending on the type of experienced event

\begin{tabular}{|c|c|c|c|c|c|c|c|c|}
\hline \multirow[t]{2}{*}{ Variable } & \multicolumn{2}{|c|}{$\begin{array}{l}\text { Oncology } \\
\text { patients }\end{array}$} & \multicolumn{2}{|c|}{$\begin{array}{c}\text { Female victims } \\
\text { of domestic } \\
\text { violence }\end{array}$} & \multicolumn{2}{|c|}{ Paramedics } & \multirow[t]{2}{*}{$F$} & \\
\hline & M & $S D$ & $M$ & $S D$ & M & $S D$ & & \\
\hline Intrusive ruminations & 16.49 & 8.72 & 18.62 & 7.68 & 7.97 & 6.39 & 39.16 & $1,2>3$ \\
\hline Deliberate ruminations & 14.98 & 6.67 & 19.16 & 7.35 & 10.40 & 6.06 & 31.98 & $\begin{aligned} 1,2 & >\text { and } \\
2 & >1\end{aligned}$ \\
\hline Posttraumatic growth - overall & 63.32 & 16.04 & 55.30 & 21.64 & 39.73 & 20.51 & 25.51 & $\begin{array}{c}1,2>3 \text { and } \\
1>2\end{array}$ \\
\hline changes in self-perception & 23.83 & 7.27 & 23.51 & 10.39 & 17.54 & 9.56 & 10.35 & $1,2>3$ \\
\hline $\begin{array}{l}\text { changes in relations with } \\
\text { others }\end{array}$ & 23.96 & 6.10 & 18.44 & 7.95 & 13.18 & 7.91 & 36.47 & $1,2>3$ \\
\hline appreciation of life & 10.22 & 3.50 & 8.93 & 3.90 & 7.17 & 3.72 & 11.58 & $1,2>3$ \\
\hline spiritual changes & 5.28 & 3.02 & 4.40 & 3.20 & 1.83 & 2.36 & 25.96 & $1,2>3$ \\
\hline
\end{tabular}

acter, and the intensity of positive posttraumatic changes, i.e. posttraumatic growth. Analyses performed for the entire group of participants suggest the importance of both types of rumination in the process of occurrence of positive changes, though the correlation coefficients are somewhat higher for deliberate ruminations. When analysing separate groups of participants, the picture of the relationships seems more complex. Among the oncology patients, significant relations were observed between growth and both types of rumination. However, taking into account separate factors which compose posttraumatic growth, one can observe that deliberate ruminations are positively correlated with pos- itive changes in terms of relations with others and the appreciation of life, and there are no such correlations with intrusive ruminations. In the group of women who had experienced violence, positive correlations with posttraumatic growth were observed only for deliberate ruminations. Similar relationships were observed for the investigated paramedics, among whom higher correlation coefficients were observed.

The next step was to check which of the two types of ruminations (intrusive or deliberate) predicts posttraumatic growth, when also taking into account its separate domains. Regression analysis for all participants taken together, as well as separate groups of

Table 4

Correlation coefficients between ruminations and posttraumatic growth

\begin{tabular}{|c|c|c|c|c|c|c|c|c|}
\hline \multirow[t]{3}{*}{ Variable } & \multicolumn{2}{|c|}{$\begin{array}{l}\text { Across all subjects } \\
\qquad(n=227)\end{array}$} & \multicolumn{2}{|c|}{$\begin{array}{l}\text { Oncology patients } \\
\qquad(n=71)\end{array}$} & \multicolumn{2}{|c|}{$\begin{array}{l}\text { Female victims of } \\
\text { domestic violence } \\
\qquad(n=89)\end{array}$} & \multicolumn{2}{|c|}{$\begin{array}{l}\text { Paramedics } \\
\quad(n=67)\end{array}$} \\
\hline & \multicolumn{2}{|c|}{ ruminations } & \multicolumn{2}{|c|}{ ruminations } & \multicolumn{2}{|c|}{ ruminations } & \multicolumn{2}{|c|}{ ruminations } \\
\hline & intrusive & deliberate & intrusive & deliberate & intrusive & leliberate & intrusive & deliberate \\
\hline $\begin{array}{l}\text { Posttraumatic } \\
\text { growth - overall }\end{array}$ & $.31^{* * *}$ & $.36^{* * *}$ & $.27^{*}$ & $.28^{*}$ & .07 & $.22^{*}$ & .22 & $.43^{* * *}$ \\
\hline $\begin{array}{l}\text { changes in } \\
\text { self-perception }\end{array}$ & $.26^{* * *}$ & $.33^{* * *}$ & .18 & .20 & .08 & $.23^{*}$ & .23 & $.35^{* *}$ \\
\hline $\begin{array}{l}\text { changes in } \\
\text { relations with } \\
\text { others }\end{array}$ & $.29^{* * *}$ & $.33^{* * *}$ & .24 & $.28^{*}$ & -.01 & $.22^{*}$ & .17 & $.43^{* * *}$ \\
\hline $\begin{array}{l}\text { appreciation } \\
\text { of life }\end{array}$ & $.24^{* * *}$ & $.30^{* * *}$ & .25 & $.28^{*}$ & .04 & .16 & .23 & $.41^{* * *}$ \\
\hline $\begin{array}{l}\text { spiritual } \\
\text { changes }\end{array}$ & $.28^{* * *}$ & $.19^{* *}$ & .19 & .07 & .07 & -.02 & .08 & .20 \\
\hline
\end{tabular}


participants, confirmed the importance of deliberate ruminations.

Deliberate ruminations turned out to predict the overall posttraumatic growth score in the entire group - they explained $13 \%$ of the variance of the dependent variable $\left(\beta=.27, R^{2}=.13\right)$. This type of ruminations also allowed the prediction of the occurrence of positive changes in terms of self-perception $\left(\beta=.27, R^{2}=.11\right)$, relations with others $\left(\beta=.25, R^{2}=.11\right)$ and appreciation of life $\left(\beta=.25, R^{2}=.09\right)$. In turn, intrusive ruminations are of significant importance for the occurrence of positive changes in the spiritual domain, explaining $7 \%$ of the variance of this variable $\left(\beta=.28, R^{2}=.07\right)$.

Taking into account the separate groups of participants, the results confirmed a significant role of deliberate ruminations in the process of occurrence of positive posttraumatic changes, most of all among paramedics and in the group of women who had experienced violence. Among the paramedics, deliberate ruminations predicted both the overall PTGI score $\left(\beta=.46, R^{2}=.18\right)$, explaining $18 \%$ of variance in this variable, and its separate domains, i.e. changes in perception of self $\left(\beta=.35, R^{2}=.12\right)$, relations with others $\left(\beta=.43, R^{2}=.18\right)$ and appreciation of life $\left(\beta=.41, R^{2}=.17\right)$.

Among women who had experienced violence, deliberate ruminations predicted the overall PTGI score $\left(\beta=.22, R^{2}=.05\right)$ and positive changes in two areas, i.e. perception of self $\left(\beta=.23, R^{2}=.05\right)$ and relations with others $\left(\beta=.22, R^{2}=.05\right)$. Among cancer patients, deliberate ruminations predicted positive changes only in relations with others $\left(\beta=.28, R^{2}=.07\right)$, explaining $7 \%$ of the variance of the dependent variable.

\section{DISCUSSION AND CONCLUSIONS}

Obtained results suggest that positive changes occur in individuals who have experienced traumatic events. However, most of the participants (over 47\%) exhibited low levels of posttraumatic growth (slightly over $31 \%$ of participants had average levels and $21 \%$ had high levels). Women exhibited higher levels of positive posttraumatic changes. Among the three groups of participants, the highest scores, in terms of posttraumatic growth, were observed in oncology patients, while the lowest were observed in paramedics. This result is in line with previous research, which suggested that individuals who are at risk of being exposed to traumatic events in connection with their work exhibit lower levels of posttraumatic growth, in comparison to individuals for whom the trauma occurs suddenly and unexpectedly (Ogińska-Bulik \& Juczyński, 2010).

Participants exhibited average levels of ruminations, both intrusive and deliberate, with women scoring higher than men for both types of rumina- tions. With regards to the type of ruminations, the highest tendency for ruminations was observed in women who had experienced violence, and the lowest was shown by paramedics.

Our results confirmed the existence of positive correlations between ruminations, especially of a deliberate character, and the intensity of posttraumatic growth. These types of ruminations were associated with posttraumatic growth in paramedics and women who had experienced violence. In turn, intrusive ruminations were not associated with the intensity of positive posttraumatic changes. However, among oncology patients, both types of ruminations were positively correlated with levels of posttraumatic growth.

Ruminations seem to have a diverse role in separate areas of posttraumatic growth. Deliberate ruminations allow for the prediction of positive changes, predominantly in the area of self-perception, but also in relations with others and appreciation of life. On the other hand, intrusive ruminations are of importance for the occurrence of positive changes in the spiritual domain.

The results are in line with most of the research presented in the introduction, which emphasizes the importance of deliberate ruminations in the occurrence of positive effects of experienced trauma. The tendency to ruminate about an experienced event may be initially associated with higher levels of distress and increased negative emotions (especially in the case of intrusive ruminations), but later on (when intrusive ruminations turn into deliberate ruminations) they foster searching for ways to cope with the experienced event and emotions, which, in effect, serves for working through the trauma and the occurrence of growth-type changes. However, the occurrence of deliberate ruminations requires time. Usually, they occur later than intrusive ruminations. Helgeson et al. (2006) stressed that time needed for examining the problem may serve for working through the trauma, giving it new meaning, and so contributes to the occurrence of posttraumatic growth.

The positive role of ruminations in posttraumatic growth, especially those of a deliberate character, may come from the fact that individuals who have experienced trauma may prefer other cognitive strategies for coping, including positive reappraisal, concentration on the problem, appeal to religion, and attributing special meaning to the experienced situations (Cann et al., 2011). One can also suppose that stable properties of an individual, in particular those associated with their personality, may play a part here - especially a deliberate style of functioning, which, on one hand, may directly foster the occurrence of positive posttraumatic changes, and, on the other, may contribute to choosing more efficient strategies of coping. One should not neglect the role of favourable social support, which may en- 
courage ruminating about an experienced event and have a positive impact on the occurrence of positive changes (Ogińska-Bulik, 2013b).

The current research has some limitations. One is the cross-sectional character of the study, which does not allow for the making of unequivocal inferences about cause-effect relationships. The negative consequences of experienced traumatic events, e.g. symptoms characteristic of posttraumatic stress disorder, were not analyzed. It should be noted that the tools that were used are based on self-reporting, leading to the possibility of bias due to the possible involvement of the social approval variable.

Despite the aforementioned limitations, it should be stressed that the presented results provide new information about the determinants of posttraumatic growth. They confirm the importance of cognitive processes, in particular deliberate ruminations, involved in the occurrence of positive effects of experienced trauma. Researching cognitive processes, including ruminations, serves for a better understanding of the mechanisms responsible for the consequences of experienced trauma.

However, further research is recommended, which should take into account, among other factors, the simultaneous influence of cognitive processes and personal resources as well as the applied coping strategies on posttraumatic growth. Our results may also be of importance in clinical practice. Encouraging individuals who have experienced trauma to ruminate about the experienced event, especially in a deliberate manner, may foster the occurrence of positive posttraumatic changes.

It is also worth noting the similarities between ruminations, especially of the intrusive type, and intrusions, which are one of the symptoms of PTSD. However, these two terms do not mean the same thing. Intrusions refer to recurrent thoughts (as do ruminations), images and emotions associated with trauma, they portray the experience of the trauma itself, and, as emphasized by Ehring and Ehlers (2014), they last for a rather short time. On the other hand, ruminations are considered to be a string of thoughts that are a result of the experienced events, and last longer in time. Many studies suggest a positive correlation between intrusions and the occurrence of positive posttraumatic changes (Helgeson et al., 2006; Ogińska-Bulik, 2013a, 2014, 2015). This suggests the need for a somewhat different outlook on the importance of cognitive processes (intrusions and ruminations), which were previously treated solely as indicators of pathology. The analysis of the problem from the perspective of positive psychology suggests that such processes may - at least to some extent - be favourable for an individual and foster their development. It does not mean, however, that experiencing trauma is something good or desired. Posttraumatic growth is not equivalent to a sense of happiness. Nonetheless, it may be an opportunity to lead a more meaningful and valuable life.

\section{ENDNOTES}

1 Positive posttraumatic changes are more widely discussed in the book Pozytywne skutki doświadczeń traumatycznych, czyli kiedy łzy zamieniaja się w perty [Positive consequences of traumatic experiences - when tears become pearls] by N. Ogińska-Bulik.

\section{REFERENCES}

Baryła, W., \& Wojciszke, B. (2005). Kwestionariusz Ruminacji [Rumination Questionnaire]. Studia Psychologiczne, 43, 5-22.

Bower, J. E., Kemeny, M. E., Taylor, S. E., \& Fahey, J. L. (1998). Cognitive processing, discovery of meaning, CD4 decline, and AIDS-related mortality among bereaved HIV-seropositive men. Journal of Consulting and Clinical Psychology, 66, 979-986.

Boyraz, G., Home, S. G., \& Sayger, T. V. (2010). Finding positive meaning after loss: The mediating role of reflection for bereaved individuals. Journal of Loss and Trauma, 15, 242-258.

Calhoun, L. G., Cann, A., Tedeschi, R. G., \& McMillan, J. (2000). A correlational test of the relationship between posttraumatic growth, religion, and cognitive processing. Journal of Traumatic Stress, 13, 521-527.

Calhoun, L. G., Cann, A., Tedeschi, R. G., \& McMillan, J. (2010). The posttraumatic growth model: Sociocultural considerations. In: T. Weiss \& R. Berger (eds.), Posttraumatic growth and culturally competent practice (pp. 1-14). Hoboken, NJ: John Wiley.

Cann, A., Calhoun, L. G., Tedeschi, R G., \& Solomon, D. T. (2010). Posttraumatic growth and depreciation as independent experiences and predictors of well-being. Journal of Loss and Trauma, $15,151-166$.

Cann, A., Calhoun, L. G., Tedeschi, R. G., Triplett, K. N., Vishnevsky, T., \& Lindstrom, C. M. (2011). Assessing posttraumatic cognitive processes: the Event Related Rumination Inventory. Anxiety, Stress \& Coping, 24, 137-156.

Carboon, I., Anderson, V. A., Pollard, A., Szer, J., \& Seymour, J. F. (2005). Posttraumatic growth following a cancer diagnosis: Do world assumptions contribute? Traumatology, 11, 269-283.

Chan, M. W., Ho, S. M., Tedeschi, R. G., \& Leung, C. W. (2011). The valence of attentional bias and cancer-related rumination in posttraumatic stress and posttraumatic growth among women with breast cancer. Psycho-Oncology, 20, 544-552.
The role of rumination in the occurrence of positive effects of experienced traumatic events 
Ehlers, A., \& Clark, D. M. (2000). A cognitive model of posttraumatic stress disorder. Behaviour Research and Therapy, 38, 319-345.

Ehring, T., \& Ehlers, A. (2014). Does rumination mediate the relationship between emotion regulation ability and posttraumatic stress disorder? Psychotraumatology, 5, 23547. Retrieved from http:// dx.doi.org/10.3402/ejpt.v.523547

Gangstad, B., Norman, P., \& Barton, J. (2009). Cognitive processing and posttraumatic growth following stroke. Rehabilitation Psychology, 54, 69-75.

Nina Ogińska-Bulik

Gerwe, E. J. (2014). Intrusive and deliberate rumination predict posttraumatic growth in members enrolled in a cardiovascular rehabilitation program. Theses and dissertation. University of South Carolina. Retrieved from http://scholarcommons.sc.edu/aiken_psychology_theses

Helgeson, V. S., Reynolds, K. A., \& Tomich, P. L. (2006). A meta-analytic review of benefit finding and growth. Journal of Consulting and Clinical Psychology, 74, 797-816.

Jarmakowski, T. (2011). Rola myślenia ruminacyjnego w podatności na wyuczoną bezradność [The role of ruminative thinking in susceptibility to learned helplessness]. Studia Psychologiczne, 49, 61-72.

Kilmer, R. P., \& Gil-Rivas, V. (2010). Exploring posttraumatic growth in children impacted by Hurricane Katrina: Correlates of the phenomenon and developmental considerations. Child Development, 81, 1211-1227.

Kleim, B., \& Ehlers, A. (2009). Evidence for a curvilinear relationship between posttraumatic growth and posttraumatic depression and PTSD in assault survivors. Journal of Traumatic Stress, 22, 45-52.

Lindstrom, C. M., Cann, A., Calhoun, L. G., \& Tedeschi, R. G. (2013). The relationship of core beliefs challenge, rumination, disclosure, and sociocultural elements to posttraumatic growth. Psychological Trauma: Theory, Research, Practice, and Policy, 5, 50-55.

Martin, L. M., \& Tesser, A. (1996). Clarifying our thoughts. In R. S. Dyer (ed.), Ruminative thoughts: Advances in social cognition (pp. 189-209). Mahwah, NJ: Lawrence Erlbaum Associates Publishers.

McIntosh, W. D., \& Martin, L. L. (1992). The cybernetics of happiness: The relation between goal attainment, rumination, and affect. Review of Personality and Social Psychology, 14, 222-246.

Michael, S. T., \& Snyder, C. R. (2005). Getting unstuck: The roles of hope, finding meaning, and rumination in the adjustment to bereavement among college students. Death Studies, 29, 435-458.

Morris, B., \& Shakespeare-Finch, J. (2011). Rumination, posttraumatic growth, and distress: structural equation modeling with cancer survivors. Psycho-Oncology, 20, 1176-1183.

Nightingale, V. R., Sher, T. G., \& Hansen, N. B. (2010). The impact of receiving an HIV diagnosis and cognitive processing on psychological distress and posttraumatic growth. Journal of Traumatic Stress, 23, 452-460.

Nolen-Hoeksema, S. (2000). The role of rumination in depressive disorders and mixed depressive /anxiety symptoms. Journal of Abnormal Psychology, 109, 504-511.

Nolen-Hoeksema, S., Wisco, B. E., \& Lyubomirsky, S. (2008). Rethinking rumination. Perspective on Psychological Science, 3, 400-424.

Ogińska-Bulik, N. (2013a). Pozytywne skutki doświadczeń traumatycznych, czyli kiedy tzy zamieniaja się $w$ perty [Positive effects of traumatic experiences - when tears become pearls]. Warszawa: Wyd. Difin.

Ogińska-Bulik, N. (2013b). The role of social support in people struggling with cancer. Health Psychology Report, 1, 1-8.

Ogińska-Bulik, N. (2014). Rola objawów stresu pourazowego w rozwoju po traumie u pracowników służb ratowniczych [The role of posttraumatic stress disorder symptoms in posttraumatic growth among rescue-service workers]. In I. Janicka \& M. Znajmiecka-Sikora (eds.), Rodzina i kariera [Family and Career] (pp. 389-402). Łódź: Wyd. UŁ. Ogińska-Bulik, N. (2015). Dwa oblicza traumy negatywne i pozytywne skutki zdarzeń traumatycznych u pracowników stużb ratowniczych [Two faces of trauma - the negative and positive effects of traumatic experiences among rescue-service workers]. Warszawa: Wyd. Difin.

Ogińska-Bulik, N., \& Juczyński, Z. (2010). Rozwój potraumatyczny - charakterystyka i pomiar [Postraumatic growth - characteristics and measurement]. Psychiatria, 7, 129-142.

Ogińska-Bulik, N., \& Juczyński, Z. (2015). Inwentarz Ruminacji o Negatywnym Zdarzeniu - polska adaptacja the Event Related Rumination Inventory [Inwentarz Ruminacji o Negatywnym Zdarzeniu - Polish adaptation of the Event Related Rumination Inventory]. Przeglad Psychologiczny, 58, 383-400.

Park, C. L., Chmielewski, J., \& Blank, T. O. (2010). Posttraumatic growth: Finding positive meaning in cancer survivorship moderates the impact of intrusive thoughts on adjustment in younger adults. Psycho-Oncology, 19, 1139-1147.

Phelps, L. F.,Williams, R. M., Raichle, K. A.,Turner, A.P., \& Ehde, D. M. (2009). The importance of cognitive processing to adjustment in the first year following amputation. Rehabilitation Psychology, 53, 28-38.

Radoń, S. (2014). Kwestionariusz Ruminacji-Refleksyjności - polska adaptacja the Rumination-Reflection Questionnaire [Kwestionariusz Ruminacji-Refleksyjności - Polish adaptation of the Rumination-Reflection Questionnaire]. Psychoterapia, 169, 61-72. 
Salsman, J. M., Segerstrom, S. C., Brechting, E. H., Carlson C. R., \& Andrykowski M. A. (2009). Posttraumatic growth and posttraumatic stress disorder symptomatology among colorectal cancer survivors: A 3 month longitudinal examination of cognitive processing. Psycho-Oncology, 18, 30-41.

Senol-Durak, E., \& Ayvasik, H. B. (2010). Factors associated with posttraumatic growth among myocardial infarction patients: Perceived social support. perception of the event and coping. Journal of Clinical Psychology in Medical Settings, 17, 150-158.

Stockton, H. (2012). Cognitive processing and growth following trauma. Thesis submitted to the University of Nottingham for the degree of doctor of philosophy. eprints.nottingham. ac.uk/28063/1/580179.pdf (accessed 20.04.2015).

Stockton, H., Hunt, N., \& Joseph, S. (2011). Cognitive processing, rumination and posttraumatic growth. Journal of Traumatic Stress, 24, 85-92.

Taku, K., Calhoun, L. G., Cann, A., \& Tedeschi, R. G. (2008). The role of rumination in the coexistence of distress and posttraumatic growth among bereaved Japanese university students. Death Studies, 32, 428-444.

Taku, K., Cann, A., Tedeschi, R. G., \& Calhoun, L. G. (2009). Intrusive versus deliberate rumination in posttraumatic growth across US and Japanese samples. Anxiety, Stress \& Coping, 22, 129-136.

Tedeschi, R. G., \& Calhoun, L. G. (1996). The Post-Traumatic Growth Inventory: Measuring the positive legacy of trauma. Journal of Traumatic Stress, 9, 455-471.

Tedeschi, R. G., \& Calhoun, L. G. (2004). Posttraumatic growth: Conceptual foundations and empirical evidence. Psychological Inquiry, 15, 1-8.

Tedeschi, R. G., \& Calhoun, L. G. (2007). Podejście kliniczne do wzrostu po doświadczeniach traumatycznych [Clinical approach towards posttraumatic growth]. In P. A. Linley \& S. Joseph (eds.), Psychologia pozytywna w praktyce [Positive Psychology in Practice] (pp. 230-248). Warszawa: PWN.

Treynor, W., Gonzalez, R., \& Nolen-Hoeksema, S. (2003). Rumination reconsidered: A psychometric analysis. Cognitive Therapy and Research, 27, 247-259.

Watkins, E. R. (2008). Constructive and unconstructive repetitive thought. Psychological Bulletin, 134, 136-206. 